\title{
Testimonio nicaragüense: de los Sandinistas a la inclusión de los Contras. Por una polémica memoria contrarrevolucionaria
}

Nicaraguan testimony: from Sandinistas to the Contras inclusion. A polemic

counter-revolutionary memory

\author{
VERÓNICA RUEDA ESTRADA \\ UNIVERSIDAD DE QUINTANA ROO • vrueda@uqroo.edu.mx
}

Profesora investigadora de la Universidad de Quintana Roo (UQROO) especializada en la historia contemporánea de Nicaragua utilizando la metodología cualitativa de la historia oral y el testimonio; su última publicación es el libro (2015): Recompas, Recontras, Revueltos y Rearmados. Posguerra y conflicto por la guerra en Nicaragua.

\section{JuAN Carlos VÁZqueZ MEDELES}

\section{GLASGOW UNIVERSITY • vazquezjc@gmail.com}

Candidato a Doctor en Estudios Latinoamericanos por la UNAM, especializado en las representaciones culturales del proceso armado en Centroamérica. Su última publicación es: "Universidad, muralización y fotografía. Legado artístico de la insurgencia en Guatemala" y "El clavel rojo: atributo del mártir revolucionario en Guatemala”.

Resumen: El presente artículo propone hacer visible el testimonio del movimiento contrarrevolucionario mismo que ha sido excluido del memorial nicaragüense. Se trata de una serie de testimonios de los Contras que han sido marginados tanto de los discursos oficiales del Frente Sandinista de Liberación Nacional (FSLN) como del discurso contrarrevolucionario. La memoria de estos combatientes antirrevolucionarios fue aplastada doblemente, por un lado, los "Freedom Fighter" fueron concebidos como subordinados del imperio norteamericano por lo que su voz se omitió por su naturaleza antagónica del gobierno sandinista; por el otro, para sus dirigentes su discurso merecía ser transmitido solo como propaganda anticomunista.

Palabras clave: Testimonio, Contra, sandinismo, anti-sandinismo.
Resumen: The purpose of this article is to bring to the fore the testimony of the Contras movement that has been excluded from the Nicaraguan memorial. These are the testimonies which have been removed from official speeches by the Sandinista National Liberation Front (FSLN) and the counterrevolution discourse. The memory of these anti-revolutionary fighters was crushed twice: first when the "Freedom Fighter" was depicted as a subordinate of the American empire so that this voice would be omitted by the antagonistic nature of the Sandinista government and second as political leaders used these discourses only as anti-communist propaganda.

Palabras clave: Testimony, Contra, sandinista, antisandinismo. 
Verónica Rueda y Juan Carlos Vázquez. Testimonio nicaragüense...

\section{Antecedentes}

El testimonio ha sido considerado como parte de la configuración del paradigma revolucionario sandinista, de la misma manera en que el sandinismo se volvió el modelo exitoso de los movimientos de izquierda en la región centroamericana -desde finales de los años setenta hasta principios de los años noventa- e incluso de todo el continente, puesto que representó la última revolución triunfante de un mundo bipolar. La escritura testimonial pretendió dar voz al subalterno, al otro, al sujeto popular ausente de la historia y de los discursos oficiales, al incluir estas voces se buscó construir una nueva historia con la presencia del pueblo, de las identidades y de las colectividades marginales como sujetos históricos y como protagonistas de los procesos de liberación nacional. Con esta idea en mente se construyó el canon testimonial, y desde esa postura ideológica se impulsaron una serie de textos que contenían el arquetipo que enarbolaron las izquierdas de la región, desde los protagonistas de la Revolución Cubana hasta las luchas contra los gobiernos dictatoriales civiles o militares de Centro y Sudamérica.

Así, junto con la agudización del conflicto bélico en Centroamérica se dio el auge del género testimonial en esta zona, ya que este se instrumentalizó por parte de los rebeldes como transmisor de sus propósitos ideológicos y de su propia lucha. La literatura y, específicamente, el testimonio fueron considerados como un medio operativo para lograr la solidaridad internacional. Durante este periodo, las obras enarboladas por la izquierda armada anularon la figura del escritor y en muchas ocasiones la del individuo, poniendo en preponderancia a las colectividades. El lenguaje en estos escritos rescata y se asume la experiencia colectiva como una concepción contrastante a las ya de por si totalizantes ideas de Nación o de Estado, se exalta la mística rebelde, se devela y se da voz a los usualmente desplazados o excluidos de la cultura dominante (el indígena, el campesino, las mujeres, los ancianos, los niños, el proletario y todos los que sufren opresión) con una fuerte carga ideológica y propagandística, en busca de un destinatario solidario.

El testimonio se consideró como la literatura de compromiso de un grupo de intelectuales de izquierda ante la realidad opresiva, y como rescate de los actos heroicos de un pueblo que combatió en pro de un futuro revolucionario. El campo cultural que configuraron las instituciones creadas a partir de la Revolución Cubana incluyó la instauración del socialismo como un proyecto de las organizaciones políticas de izquierda en América Latina, y exigió como praxis revolucionaria el compromiso militante de la intelectualidad, tal como lo afirma Carlos Monsiváis: "La militancia se predica y se exige. A los intelectuales y artistas se les ofrece un destino muy alto: oponer sus obras y sus ejemplos a las devastaciones del imperialismo" (2000: 74). El testimonio entonces se transmitió como la verdadera literatura que a su vez difundió la representación del revolucionario latinoamericano, y la revista literaria 
Verónica Rueda y Juan Carlos Vázquez. Testimonio nicaragüense...

cubana Casa de las Américas lo institucionalizó y fungió como el principal transmisor (Ochando, 1995: $167)$.

El testimonio se convierte, entonces, en la tendencia genérica característica de Centroamérica en cuanto a su estrecha vinculación con los movimientos antidictatoriales. Como parte integral de la propia resistencia "no solo relatan estrategias de resistencia; son en sí mismas una de estas estrategias" (Harlow, 1999: 125). Esta literatura, que también adquirió una función catártica, tuvo una gran aceptación debido a la riqueza de experiencias que representaba la historia reciente y las circunstancia de lucha en el istmo centroamericano. En efecto, Guatemala, El Salvador y Nicaragua, Costa Rica, Honduras y Panamá (los últimos tres en menor medida) estaban marcadas por grandes y bruscos cambios sociopolíticos: la lucha antidictatorial, la guerrilla, la instauración de políticas antisubversivas con el apoyo de Estados Unidos y, en el caso nicaragüense, primero los años de gobierno revolucionario y luego la guerra contrarrevolucionaria. En todos los casos los testimonios hacen referencia a realidades concretas, extra literarias, producto de la estrecha relación entre lo social y las letras.

Se trata de textos altamente politizados que podrían llamarse "máquinas de ataque ideológico”, un instrumento de propaganda política enarbolado por la izquierda revolucionaria. En este paradigma de solidaridad que se impulsó en los movimientos de liberación nacional evidentemente no tuvieron lugar los textos de La Contra ${ }^{1}$, pues se trató de una propuesta política contraria a la revolución. Dicho proyecto fue visto como una expresión más de la "barbarie" de un sector reaccionario y poco representativo de la población, cuya característica principal era su conservadurismo y su alineación con los intereses de la dictadura, además estos grupos se oponían de manera violenta al cambio revolucionario y a sus buenas nuevas. Si bien, La Contra no fue un grupo unificado -como tampoco lo fueron los sandinistas pues el Frente Sandinista de Liberación Nacional (FSLN) se fundó en 1961 y en los años setenta se fragmentó en tres tendencias políticas, mismas que en marzo de 1979 se reunificaron- sus miembros compartían ideales liberales que eran bien conocidos tanto en los discursos políticos de Nicaragua como en general en la zona, sintetizados en los conceptos de: Libertad, Democracia, Dios, Patria y finalmente el Anticomunismo.

Para el gobierno sandinista el discurso de La Contra estaba basado en versiones incorrectas de su proyecto revolucionario pues rechazaba la construcción del socialismo desde el Estado y la institucionalización de la revolución sandinista como parte de una tradición heredada por el líder

\footnotetext{
${ }^{1}$ Contra, La Contra o los Contras, son las formas en que se nombró a los contrarrevolucionarios (independientemente de la organización a la que pertenecieran) y en general a la contrarrevolución nicaragüense, no se trata de un término despectivo y ellos mismos no tuvieron inconveniente en ser llamados así, aunque la forma oficial para designar a la organización es Resistencia Nicaragüense (RN).
} 
nacionalista de principios del Siglo XX Augusto C. Sandino. Otra razón del rechazo al discurso contrarrevolucionario fue que era una versión de democracia que se difundía y financiaba desde Estados Unidos $^{2}$. Como contraste, para los sectores contrarrevolucionarios, los términos utilizados en la época por la izquierda: marxismo, comunismo y socialismo eran simplemente sinónimos pues no diferenciaban los matices y no les interesaba hacerlo debido a su liberalismo tradicional que exigía combatirlos y exterminarlos. En el presente trabajo no se pretende realizar un debate sobre el proyecto político e ideológico de La Contra, sino por el contrario puntualizar el silencio discursivo -pocas veces roto- que se estableció sobre el mismo, ello a pesar de tratarse de la propuesta ideológica de una organización político-militar fundamental para entender el conflicto nicaragüense.

Ambos discursos testimoniales, los enunciados por los sandinistas y los pocos realizados por los contras, contienen en sí una voz marginal, subalterna misma que se sitúa en una colectividad subsumida en un espacio geográfico y en una realidad histórica concreta. Ambos, con sus diferencias, actúan dentro de un campo de batalla ideológico, sujetos a dos paradigmas contrarios: marxismo contra liberalismo, comunismo contra anticomunismo, ateísmo contra religión, sandinismo contra antisandinismo ${ }^{3}$. Es decir, la autorrepresentación identitaria que contienen las obras testimoniales en su propio espacio de producción implica una intersección con una identidad colectiva, vista a sí misma como una cultura subalterna, en contraste con la cultura dominante o hegemónica -constituida desde el sandinismo frente a la dictadura familiar somocista o desde La Contra frente al gobierno sandinista-, dicha intersección o punto de tensión configura dos discursos que se contraponen políticamente y que puntualizan la ineficacia e ilegitimidad del Estado -independientemente de sus características políticas- para develarse frente a esta colectividad, para exigir reconocimiento y situarse como legitimo frente a la construcción de la Nación, o mejor dicho, de la Nueva Nación. Si bien el fin de la guerra en 1990 no trajo la derrota de ninguna de las dos partes y es considerada oficialmente como un empate sin vencedores ni vencidos, la batalla ideológica fue perdida por La Contra pues su discurso quedó nuevamente subsumido en la vorágine de la posguerra y su discurso de paz y reconciliación.

Los testimonios Contras también fueron marginados del discurso académico principalmente porque su contenido estaba elaborado desde la derecha, esta característica rompía con el paradigma del testimonio de la región anclado en lo popular, liberador y de resistencia a las injusticias del sistema

\footnotetext{
${ }^{2}$ Durante su década de existencia, La Contra fue financiada principalmente por el gobierno norteamericano, aunque en sus inicios también contó con el apoyo de los militares argentinos y hondureños.

3 Aunque la revolución sandinista es sumamente religiosa, o toma elementos religiosos como forma de cohesión discursiva, se separan en la interpretación tradicional del evangelio. Para entender esta visión cristiana del sandinismo puede verse: Cristianos en la revolución (1983) de Margaret Randall y Revolucionarios por el evangelio de Teofilo Cabrestero (1983), este último con prólogo del Obispo de Sao Felix, Brasil Pedro Casaldaliga y el testimonio de 15 cristianos en el gobierno revolucionario.
} 
(aunque se opusieran a las injusticias que pudieron generar los sandinistas), aún en la actualidad estos testimonios no han sido suficientemente estudiados, lo que devela la negación de La Contra, de su proyecto y de su voz, como una colectividad política presente en Nicaragua. Estos testimonios, sin embargo, están luchando desde su enunciación por ser reconocidos dentro de ese contexto de guerra y de posguerra.

La "Teoría de los dos demonios" afirma que la violencia en la Argentina fue perpetrada tanto por el estado como por las fuerzas guerrilleras (Franco, 2014), y está ampliamente difundida en Centroamérica. Siguiendo esa línea argumental, en Nicaragua equivaldría a reconocer que la violencia ejercida en los años ochenta fue tan brutal tanto por los sandinistas como por La Contra. Este artículo no busca equiparar ambas fuerzas militares como igualmente violentas, simplemente propone visibilizar el discurso de una de las fuerzas contendientes que no ha sido escuchada o reconocida ampliamente, ya sea por la poca difusión de dichas obras, o por el rechazo tanto de la academia nicaragüense y centroamericana, como de la academia metropolitana que perdieron la fascinación inicial por la temática testimonial. Con este silencio académico se pierde por un lado, una importante visión de la historia y por el otro, del conocimiento de momentos, identidades y complementos de la misma. Es justo reconocer que este silencio también se debe al poco interés ideológico, político, histórico y personal de los líderes contrarrevolucionarios y Contras de bases por hacer escuchar sus voces, sus versiones y visiones.

\section{Dos momentos de la escritura testimonial sandinista ${ }^{4}$}

Una de las características más significativas del testimonio sandinista son los múltiples cambios y voces presentes en su enunciación. Antes de la derrota de Anastasio Somoza Debayle en 1979 los textos buscaban confirmar la participación de las masas populares en sus filas. Posteriormente, una vez obtenida la victoria, los testimonios tenían una estructura más cercana a la enunciación en primera persona, pues a pesar de intentar hablar de la colectividad, también se ponía énfasis en la vida y participación política y militar de los sandinistas como protagonistas-testimoniantes. Esta multiplicidad de voces concuerda con lo que el escritor y crítico guatemalteco Mario Roberto Morales señala:

Lo que ha caracterizado al Testimonio centroamericano ha sido su carácter imaginativo y multivocal, lo cual implica que de hecho puede ser una expresión multiclasista, multiétnica e

\footnotetext{
$\underline{4}$ Beverley y Zimmerman (1990) proponen la existencia en la región centroamericana de tres etapas testimoniales: la primera, denominada proto-testimonio, la segunda corresponde al testimonio sandinista y la tercera, el neo-testimonio. Esta clasificación se elaboró principalmente a través del énfasis en los temas y la época de escritura. Se sigue esta línea argumental centrándonos principalmente en el testimonio sandinista y el neo-testimonio de la posguerra pues es justo el periodo donde la Contra tuvo presencia política.
} 
Verónica Rueda y Juan Carlos Vázquez. Testimonio nicaragüense...

intercultural, y no exclusiva de la subalternidad iletrada y oral, como exige la teoría estadounidense del Testimonio (Morales, 2001).

En el testimonio nicaragüense con temática sandinista, pueden reconocerse tres vertientes temporales: La primera, la etapa pre-revolucionaria, que inicia en los años en que se construye el frente militar, son los años de lucha clandestina y de acumulación de fuerza de quienes se ostentan como herederos de Sandino a través de la creación y crecimiento del Frente Sandinista de Liberación Nacional (FSLN) como organización representativa del pueblo nicaragüense; posteriormente, la segunda etapa, la revolución triunfante continúa con el derrocamiento definitivo de la dictadura somocista y la consiguiente victoria revolucionaria con las acciones del FSLN en el poder, es entonces la década de la revolución, donde el testimonio sandinista (y algunos antisandinistas) incluye con las batallas más significativas de la población: la participación masiva en las campañas Nacional de Alfabetización, las brigadas populares para el corte de café y la contención de los grupos contrarrevolucionarios. La tercera etapa, es la posrevolución y son los testimonios de la posguerra. En general, en dicho corpus se pone el énfasis argumentativo en las circunstancias sociales originales y particulares que hicieron posible la postura política del testimoniante.

Se trata de textos generalmente narrados en primera persona y cuyo escritor era siempre diferente al que testimonia o bien, como diría el crítico literario Roberto Ferro, "una historia de vida contada por otro" (1998: 113)5 o como afirma Graciela Gliemmo "la autobiografía del iletrado" (1996) ${ }^{6}$. Se trata de narraciones de protagonistas que buscan convencer de lo verdadero y fiable del testimonio que expone y de la importancia de los hechos y lo que estos representan, al tratarse de un Otro ejemplar.

Este tipo de testimonios necesitaron de un articulador, un facilitador, un gestor (Barnet, 1969: 32 ), es decir, un mediador entre los recuerdos de este y la estructura narrativa, entre las hazañas de los combatientes y simpatizantes y el registro de esas acciones heroicas e históricas pues se trató de protagonistas populares. Un concepto que cabe perfectamente dentro de los "nuevos temas de la historia", estudiados por Michel de Certeau en "La operación histórica”: “[...] las fiestas, la literatura popular, el mundo olvidado del campesino [...] estos nuevos temas de estudios testimonian un movimiento que se perfila desde hace varios años en las estrategias de la historia” (en Perus, 1994: 60).

\footnotetext{
${ }^{5}$ Entre otras de las características más significativas de la biografía -y que comparte con el testimonio-, destacamos que se trata de narraciones mediadas que hablan de un tercero, se refieren a un hombre o mujer ejemplar cuyas ideas y acciones cambiaron el curso de la historia de una nación o del mundo, y son reivindicatorias de hazañas; su naturaleza es la didáctica de la ejemplaridad de una persona heroica y/o fundacional (Véase Molloy, 2001).

${ }^{6}$ Gliemmo lo divide en dos categorías: el mediado -cuya característica principal es que está escrito en estrecha colaboración con un Otro diferente al que da el testimonio- y el escrito por los mismos protagonistas. Sobre dicha propuesta, me parece pertinente, mencionar que al hablar del testimonio como la biografía del iletrado cae en una contradicción pues el protagonista que escribe no es entonces iletrado.
} 
En el caso nicaragüense, en el fragor de la revolución sandinista, también se hablaba de una historia opuesta a la tradicional, con temas y perspectivas diferentes. En ese contexto, la escritora estadounidense Margaret Randall, afirmó: "Posiblemente es ahora que tenemos la oportunidad de hacer historia «por primera vez en la historia»". En las etapas anteriores al capitalismo, incluyéndolo, la historia la escribían siempre las clases dominantes" (1990: 6).

Para Randall, la "nueva” historia, podía y debía ser escrita por el pueblo, una versión diferente de la hecha por la élite que, por eso mismo, sería más verdadera, al estar elaborada con base en los muchos testimonios de los protagonistas. Estos supuestos conceptuales implican una lucha por la verdad entre la que posibilita el testimonio y la afianzada de la historia oficial. Los protagonistas de la revolución en Nicaragua contaron entonces su historia para que fuera escrita desde una visión sandinista en la que obviamente participaron.

Es así que el testimonio nicaragüense se inscribe en la tradición iniciada por el cubano Miguel Barnet con Biografía de un Cimarrón (1968), en donde el autor, usando los métodos de la antropología, narra la vida de un esclavo liberto ${ }^{7}$. La propuesta tenía un gran asidero en la región centroamericana que retomaría la tradición literaria del Realismo Social. Desde una incipiente perspectiva del género recién definido (subgénero para Mackenbach, 2001), estas obras comparten la característica de la denuncia (social, económica, cultural, política e histórica), tienen una amplia difusión internacional, son una manifestación de resistencia en contra de las barbaridades cometidas por los gobiernos en las luchas contrainsurgentes, incluyen su exposición de razones para participar en la lucha de los grupos de izquierda y de los sectores populares. Quizás, su objetivo más importante sea la búsqueda de apoyo y un llamado a la solidaridad internacional, algo que podríamos considerar como un acto de recuperación de lo popular dentro de la literatura latinoamericana. Es entonces el testimonio una literatura de resistencia, contestataria del poder y, bajo ese tenor, "una de las formas discursivas más eficientes de los últimos tiempos” (Urbina, 2001). Estas obras conforman además una estética práctica (Yúdice, 1992) cuyo eje narrativo es una perspectiva histórico- biográfica ${ }^{8}$. Asimismo, introduce en el panorama de los géneros

\footnotetext{
${ }^{7}$ Para una genealogía del testimonio en Centroamérica, ver la obra de Beverley y Zimmerman Literature and Politics in the Central American Revolutions (1990), especialmente los capítulos 1 y 2 . Allí se explica cómo en la región y desde varios flancos de las literaturas "comprometidas", se luchó por denunciar las condiciones de vida denigrantes de un amplio sector de la población. Forman parte de este corpus las obras Miguel Mármol. Los sucesos de 1932 en El Salvador, de Roque Dalton (1972) y Me llamo Rigoberta Menchú y así me nació la conciencia, de Elizabeth Burgos (1983), por mencionar dos de los testimonios centroamericanos más representativos.

${ }^{8}$ En los testimonios, lo social y lo histórico, están presentes incluso de manera indisoluble en la propuesta del texto y deben ser entendidos como parte de la bipolaridad del mundo (pobres y ricos, letrados y no letrados, productores y consumidores, informados y desinformados). Las características consagradas y canonizadas del testimonio fueron el aprovechamiento de nuevas formas discursivas para expresar el compromiso socio-político y las aspiraciones estéticas e ideológicas de las elites progresistas.
} 
literarios la presencia de un hablante -en un acto de ventriloquia, diría Nicasio Urbina (2001)- que habla por otro.

El testimonio es visto como un arma de transformación social, que busca que los artistas estén comprometidos en la denuncia a la injusticia y en solidaridad con los sectores sociales y económicos más desprotegidos, y que las artes se mantengan alejadas de la burguesía y del éxito comercial ${ }^{9}$. El testimonio cabría, en lo que Nagy-Zekmi (2001) llama "literatura de resistencia”, "un género contestatario" que emerge de la marginalidad para dar una versión diferente al discurso histórico, una manifestación de puntos de vista contra -hegemónicos, para desmentir "la historia oficial" del vencedor -aunque en el caso del sandinismo ellos fueron los vencedores-. Su originalidad es proponer una visión que incluye eventos, detalles y personajes que delinean, a su vez, una nueva versión del pasado. La paradoja es que los sandinistas se volvieron gobierno y con ello el margen se volvió centro, el discurso sandinista se convirtió en oficial, y entonces un elemento de opresión y responsable de las omisiones de la historiografía oficial.

\section{a) El primer momento de la escritura testimonial sandinista: etapa pre-revolucionaria}

Este primer momento del testimonio sandinista es un proceso ideológico-literario de acumulación de fuerzas y sus resultados que se inicia cuando los sandinistas están luchando desde la clandestinidad para derrocar a la dictadura somocista, la llamaremos etapa pre-revolucionaria, se trataba de una búsqueda para crear un hilo ideológico con Sandino y con el antisomocismo, posteriormente logran vencer a las fuerzas dictatoriales y lanzan una campaña a favor del testimonio, es el momento que llamaremos de la revolución triunfante.

La etapa pre-revolucionaria inicia con la publicación en la década de 1930 de las obras Maldito País de José Román (1930); Sangre en el trópico: novela de la intervención yanqui de Hernán Robleto (1930); la entrevista de periodista Ramón Belausteguigoitia Con Sandino en Nicaragua (1934) donde además da sus impresiones de la lucha antiimperialista del líder de Las Segovias y Sandino: relato de la revolución en Nicaragua (1937) de Alfonso Alexander. En estos textos se incluyeron construcciones narrativas de la realidad social trastocada por la intervención norteamericana y lo que se vislumbraba como la instalación de la dictadura de Somoza, y la búsqueda de la solidaridad internacional ${ }^{10}$, es decir, tres de los elementos temáticos fundamentales del testimonio sandinista pre y revolucionario. Es importante resaltar que desde el poder se intentó responder a estos escritos de simpatizantes de Sandino

\footnotetext{
9 Como se verá más adelante, los testimonios sandinistas también fueron éxitos editoriales y tuvieron su “explosión” institucional con los libros editados por Vanguardia, la editorial oficial del gobierno revolucionario.

${ }^{10}$ Ejemplo de ello fue el Comité ¡Manos Fuera de Nicaragua! (MANFUENIC) organizado desde México en 1929 y en el que participaron personalidades como Juan Antonio Mella, Pedro L. Cepeda, Diego Rivera y Tina Modotti entre otros
} 
con versiones opuestas. Así Manolo Cuadra publica Contra Sandino en las montañas (1942) y el dictador Anastasio Somoza García El verdadero Sandino o el calvario de Las Segovias (1936), una tradición editorial que seguiría posteriormente su hijo con el texto Nicaragua Traicionada en coautoría con Jack Cox (1980). Cabe recordar que ambos murieron asesinados y el del último de los Somoza fue tema de varios textos ${ }^{11}$.

La escritura testimonial también fue cultivada por el fundador del FSLN pues en los años cincuenta aparecen las experiencias de Carlos Fonseca en la obra Un nicaragüense en Moscú. Después de la represión desatada luego del asesinato de Somoza García en 1956, cobra importancia el testimonio de la barbarie dictatorial como una forma de crear conciencia de las condiciones políticas del país, ejemplo de ello son las obras de Pedro Joaquín Chamorro Cuadra, Estirpe sangrienta. Los Somoza (1957) y Diario de un preso (1963), así como Mi rebelión. La dictadura de los Somoza de Luis Gonzaga Cardenal (1961). Se trata de un periodo de acumulación de fuerza en el campo literario pues el testimonio nicaragüense se convirtió en arma y forma de lucha en contra del poder hegemónico.

Esta acumulación de fuerzas se realizó desde la clandestinidad ${ }^{12}$ dónde se "recrean los principios intelectuales-culturales primigenios de la revolución” (Delgado, 2002) pero una vez obtenido el triunfo revolucionario emergen como parte de una gran maquinaria del gobierno revolucionario, el testimonio se convirtió entonces en "[...] la forma discursiva por antonomasia” (Arellano, 1997:137) durante la década sandinista.

Por su parte, la posibilidad de entrevistar a los combatientes sandinistas cautivó a los intelectuales y periodistas que llegaron al país a observar la lucha contra el régimen dictatorial, si bien, el testimonio era ampliamente conocido en los años setenta, la manera en que se presentan y se abordan los temas desde el periodismo toman otro sesgo, aún cuando también se trate de información que denuncia y se solidarice con el movimiento, ejemplo de ello es el texto del periodista brasileño Paulo Cannabrava Filho,

\footnotetext{
${ }^{11}$ Sobre el "Tiranicidio" de Somoza Debayle existen tres versiones: la primera surgió en 1990 desde la ciudad donde ocurrió el asesinato, Asunción, y fue escrita por el antiguo amigo y colaborador del dictador, Alejandro Mella Latorre, y se titula Somoza y yo. Crónica de un calvario en Paraguay; la segunda, de tintes periodísticos, escrita por Claribel Alegría y el norteamericano D.J Flakoll, Somoza: expediente cerrado. La historia de un ajusticiamiento (1993), versión en español de Death of Somoza. The firsth person story of the guerillas who assassinated the nicaraguan dictator (1996), USA, Curbstone Press, Coneccticut; y por último, La saga de los Somoza. Historia de un magnicidio (2002) de Agustín Torres Lazo, que trata sobre los dos ajusticiamientos, el de Somoza García - pues Torres fue fiscal del caso judicial en contra de los compañeros de Rigoberto López Pérez por el asesinato-y el de Somoza Debayle.

${ }^{12}$ En este periodo merece especial atención en libro Somos millones: la vida de Doris María, combatiente nicaragüense (1977) de Margaret Randall que fue elaborado en situación de clandestinidad y exilio pero con enorme capacidad de distribución continental.
} 
Verónica Rueda y Juan Carlos Vázquez. Testimonio nicaragüense...

Tras los pasos de Sandino, publicado en las vísperas de a la debacle somocista (1978) o la crónica de Gabriel García Márquez El Asalto al Palacio Nacional (1978).

\section{b) El Segundo momento de la escritura testimonial sandinista: la revolución triunfante}

Una vez obtenida la victoria militar y derrocada la dictadura, el gobierno sandinista desplegó sus recursos humanos y económicos para ganar otra batalla, la ideológica por medio de la legitimidad de la revolución popular triunfante. Por ello pusieron el énfasis en los textos que fortalecieran la identidad de los militantes sandinistas como protagonistas de un proyecto revolucionario en curso, así la insurrección popular se vuelve uno de los mitos fundacionales del sandinismo en el gobierno, en este tenor destacan los testimonios escritos por líderes sandinistas: La montaña es algo más que una inmensa estepa verde (1982) de Omar Cabezas y La paciente impaciencia de Tomás Borge (1989), pero también era necesario hacer hablar a los protagonistas que no podían tener voz por ellos mismos, así, tempranamente, diversos intelectuales que se aglutinaron en Nicaragua en el momento en que la revolución sandinista comenzaba a establecer su política al frente del Estado, y escribieron sobre el proceso, destaca la obra de la guerrillera tupamara María Gravina Telechea que visibilizó a los infantes en la lucha antisomocista Que diga Quincho (1982); Las sandinistas (1985) de Elizabeth Maier; y el canónico La marca del Zorro del entonces vicepresidente nicaragüense Sergio Ramírez, entre muchos otros ${ }^{13}$.

Desde las editoriales del gobierno sandinista, a saber Nueva Nicaragua adscrita al Ministerio de Cultura junto con Ocarina y además Vanguardia del FSLN, se publicaron una gran cantidad de libros testimoniales. También por iniciativa gubernamental se invitó a investigadores y periodistas extranjeros, para que hicieran entrevistas a altos mandos de la dirigencia y a combatientes comunes en busca de la solidaridad internacional a la causa revolucionaria. Así, con la maquinaria gubernamental como telón de fondo ${ }^{14}$, la estadounidense Margaret Randall publicó tres libros sobre testimonios nicaragüenses, bajo una directriz de lo que hoy pudiésemos llamar perspectiva de género: Todas estamos despiertas testimonios de la mujer nicaragüense hoy (1980), Nicaragua, la mujer en la revolución (1980) y Las

\footnotetext{
${ }^{13}$ Para una descripción pormenorizada de los textos más representativos del periodo véase Rueda, 2009.

${ }^{14}$ En la introducción de Todas estamos despiertas. Testimonios de la mujer nicaragüense hoy (1980) se afirma: "El trabajo de campo [...] se llevó a cabo del 1 de noviembre de 1979 al 31 de enero de 1980. Respondió a una invitación del Ministerio de Cultura Nicaragüense, organismo que puso a mi disposición vivienda y comida, el uso de un jeep con chofer, ayuda secretarial y operativa [...]”. (1980: 9), lo que evidencia el apoyo logístico del FSLN en el proceso de elaboración de la obra.
} 
mujeres (1989). Así mismo, la académica estadounidense recogió un gran corpus de entrevistas que aportaron a la producción testimonial ${ }^{15}$.

Randall también colaboró en la creación de una serie de talleres con el fin de promover campañas literarias y brigadas culturales para animar al pueblo a recabar sus propias experiencias. La antropóloga norteamericana sistematizó sus concepciones y sus experiencias sobre el testimonio con la finalidad de desarrollar una metodología que pudiera emplearse en la realización de este tipo de obra, el manual Testimonios ${ }^{16}$-publicada paralelamente en Inglés como Testimonies: a Guide to oral History- sirvió como libro de texto en los talleres sobre historia oral, una de las primeras actividades organizadas por el recién creado Ministerio de Cultura, ahí se incluyen "consejos de escritura de Walter Benjamín, así como instrucciones básicas de cómo usar y cuidar la grabadora” (Randall, 1992: 22). El corpus de los testimonios resultantes del taller serían elementos centrales de la elaboración de "la nueva historia de Nicaragua" 17

En forma paralela a la campaña de alfabetización se llevó a cabo el proyecto de rescate histórico de la participación popular en la lucha antisomocista, a través de la cual los miembros de la Brigada de Rescate Histórico Germán Pomares Ordóñez recabaron los testimonios orales de más de 7,000 dirigentes populares, mismos que actualmente se encuentran en el Acervo de historia oral del Instituto de Historia de Nicaragua y Centroamérica (IHNCA-UCA). También se fundó el Instituto de Estudios del Sandinismo (IES) en el que los testimonios de ex -guerrilleros, militantes, colaboradores y bases de apoyo serían determinantes para rescatar la perspectiva popular. Sobre la importancia que el discurso testimonial adquirió en el gobierno sandinista John Beverley afirmó: "Puede ser que hubo demasiada nacionalización de la literatura, a la cual los sandinistas dedicaron enormes recursos estatales, a pesar de

\footnotetext{
${ }^{15}$ Los otros libros de Randall sobre Nicaragua son Cristianos en la revolución (1983a), y Testimonios (1983); - estos últimos tres elaborados directamente con apoyo del gobierno sandinista. También Somos millones. La vida de Doris María, combatiente nicaragüense (1977), Risking a Somersault in the air (1984)-conversaciones con escritores nicaragüenses, solo disponible en inglés-, Las mujeres (1989) y Las hïas de Sandino. Una historia abierta (1999).

${ }^{16}$ En 1983 aparece originalmente en una coedición del Centro de Estudios y Publicaciones Alforja de San José y la editorial Nueva Nicaragua. En 1992 en una versión corta es editada en el número especial de la Revista de crítica literaria latinoamericana sobre el testimonio, con el título “¿Qué es y cómo se hace un testimonio?” A esta edición hacemos referencia (Randall, 1992).

${ }^{17}$ En necesario hacer la siguiente aclaración pues cuatro de los siete libros de Randall en Nicaragua involucran a grandes personalidades revolucionarias; por otro lado, en los testimonios populares de Todas estamos despiertas no problematizó en la elaboración del texto la situación vertical que representaba una mujer extranjera con el poder sandinista detrás y la influencia que ejercía en las testimoniantes "subalternas". En ese sentido, su manual también puede verse como una clara imposición sobre la manera en que debían hacerse los testimonios, puesto que ella les enseñó a "los de abajo" cómo hacer su propia "historia" para que esta cuadrara en los parámetros previamente establecidos por la misma Randall. Esta crítica no pretende minimizar la trascendental labor de Margaret Randall.
} 
las crecientes crisis económica [...]” (en Roman, 1999: 20). Pese a las facilidades institucionales y a los recursos utilizados, otros testimonios del sandinismo nunca fueron publicados masiva ni extensivamente y solo existen versiones mimeografiadas que forman parte del acervo del mencionado IES y que ahora se encuentran en la colección Historia oral del IHNCA-UCA.

Si bien, el organismo cubano Casa de las Américas fungió domo difusor del género a través de su revista, así como de la creación de la categoría dentro de su concurso anual, la emergencia exponencial de dichas obras en Nicaragua no se vio reflejada en dicha Institución. Se ha mitificado la importancia de Casa de las Américas en la producción de los textos testimoniales en América Latina, particularmente en Centroamérica, sin embargo, en poco más de cuatro décadas desde la primera obra premiada La guerrilla tupamara de la uruguaya María Esther Gilio y Girón en la memoria del cubano Víctor Casaus que tuvo mención en la categoría en 1970, se han otorgado una veintena de premios ${ }^{18}$ y solo dos de las obras galardonadas correspondieron a nicaragüenses, los ya mencionados: La montaña es algo más que una inmensa estepa verde de Omar Cabezas Lacayo (1982) y La paciente impaciencia de Tomás Borge $(1989)^{19}$

Como mencionábamos anteriormente, la explosión de obras testimoniales en el país centroamericano limitó la enunciación al paradigma revolucionario sandinista, por lo que las voces

${ }^{18}$ Los ganadores en la categoría de testimonio son: Un grano de mostaza. El despertar de la revolución de Márcio Moreira Alves, Brasil (1972); Los subversivos de Antonio Caso, Brasil (1973); Huillca: habla un campesino peruano de Hugo Neira Samánez, Perú (1974); Aquí se habla de combatientes y de bandidos de Raúl González de Cascorro, Cuba (1975); Cerco de Púas de Aníbal Quijada Cerda, Chile (1977); Días y noches de amor y de guerra de Eduardo Galeano, Uruguay (1978); El que debe vivir de Marta Rojas, Cuba (1978); Los dias de la selva de Mario Payeras, Guatemala (1980); corresponsales de guerra de Fernando Pérez Valdés, Cuba (1981); Me llamo Rigoberta Menchú y así me nació la conciencia de Elizabeth Burgos Debray, Venezuela (1983); Contra el agua y el viento de Juan Almeida Bosque, Cuba (1985); Falsas, maliciosas y escandalosas reflexiones de un nángara de Alí Gómez García, Venezuela (1985); Mi general Torrijos de José de Jesús Martínez, Panamá (1987); Wadubari de Marcos A. Pellegrini, Brasil (1991); El Imperio de la Habana de Enrique Cirules, Cuba (1993); El sueño africano del Che. ¿Qué sucedió en la guerrilla congolesa? de William Gálvez Rodríguez, Cuba (1995); Rita Montaner. Testimonio de una época de Ramón Fajardo, Cuba (1997); La isla de Morgan de José Alejandro Castaño Hoyos, Colombia (2003); Oblivion de Edda Fabbri, Uruguay (2007); Mañana es lejos. Memorias verdes de los años rabiosos de Eduardo Rosenzvaig, Argentina (2009). Seis menciones: Girón en la memoria de Víctor Casaus, Cuba (1970); Amparo: millo y azucena de Jorge Calderón González, Cuba (1970); Muy buenas noches, señoras y señores de Rigoberto Cruz Díaz, Cuba (1972); Uruguay, 14 de abril de 1972 de Filomena Grieco y Carlos Rovira, Uruguay (1973); y Reyita, sencillamente de Daisy Rubiera Castillo, Cuba (1997); En el torrente de Raúl Roa Kourí, Cuba (1999). El premio extraordinario de la Juventud en Nuestra América (Contra viento y marea del Grupo Areito, Cuba-E.U. (1978); y el premio especial en Narrativa José María Arguedas fue para Diario de un clandestino de Miguel Bonasso, Argentina (2002).

${ }^{19}$ Otras obras nicaragüenses galardonas en el concurso correspondieron al cuento de Lisandro Chávez Alfaro por Los monos de San Telmo (1963); a la poesía de Gioconda Belli por Línea de fuego (1978); a Claribel Alegría por Sobrevivo (1978), aún antes del triunfo sandinista; y un solo texto premiado tocó la temática: Perfiles de la Revolución sandinista (1984) del argentino Carlos Vilas en la categoría de ensayo. 
disidentes de este no pudieron ser escuchadas ni en Nicaragua ni en Latinoamérica, esto último se debió a la propia coyuntura política de la región y a las características del modelo testimonial construido desde la izquierda revolucionaria, por lo que los testimonios no sandinistas no estuvieron presentes y se les excluyó -o desactivó- en la batalla ideológica, como instrumento de combate.

La derrota electoral del FSLN en 1990 provocó la interrupción en la publicación de testimonios, en la medida en que ya no contaron con el apoyo económico de algunas de las editoriales del gobierno y/ o del partido. Por otro lado, permitió la distribución de una serie de testimonios y obras contrarias a las políticas culturales y editoriales del sandinismo. Algunos de ellos fueron publicados en inglés, otros en español y otros más en ediciones bilingües.

\section{La postrevolución: el testimonio sandinista y antisandinista}

Con la derrota electoral de febrero de 1990 el modelo de testimonio con apoyo estatal quedó agotado y surgió la necesidad de explicar y auto explicarse el desarrollo y caída del sandinismo revolucionario. La derrota no significó el fin del testimonio sino solo su mutación a nuevas formas literarias, y se podía vislumbrar en el panorama que permitiría el ascenso de nuevos discursos sandinistas y antisandinistas, sin embargo eso no sucedió y la realidad fue un silencio testimonial, solo rotó por algunas obras de líderes sandinistas como el sacerdote trapense y ex Ministro de Cultura del gobierno revolucionario, Ernesto Cardenal, que publicó los tres tomos de sus memorias, Vida perdida (1999); Las ínsulas extrañas (2001) y La revolución perdida (2003); la poetisa Gioconda Belli con El país bajo mi piel: Memorias de amor y guerra (2001); y Sergio Ramírez con Confesión de amor (1990) y Adiós Muchachos. Una memoria de la revolución sandinista (1999).

Resulta sumamente significativo que los tres autores en distintos momentos y por posiciones similares rompieran definitivamente con el FSLN aglutinado en el caudillismo de Daniel Ortega ${ }^{20}$. El XX aniversario de la revolución sandinista les sirve de marco y de pretexto para presentarnos sus reflexiones -principalmente críticas- del período: una retrospectiva escrita entre los años de 1999 y 2001 , sobre eventos que forman parte de la historia reciente nicaragüense y que son narrados desde la problemática perspectiva del yo-escritor-memorialista y la conflictiva relación con su pasado.

\footnotetext{
${ }^{20}$ Para mayor información sobre los puntos convergentes en sus críticas al FSLN, puede verse el desplegado que firmaron juntos Cardenal, Belli y Ramírez, en contra de la candidatura de Daniel Ortega en las elecciones presidenciales de 2001: “No votaremos", en La Nación, 14 de octubre de 2001.
} 
Todas estas obras son una revelación individual en contra del olvido institucional y colectivo ${ }^{21}$. Al mismo tiempo caen en una contradicción: por un lado, intentan recuperar el pasado a través de sus memorias y, por otro y a la vez, pretenden distanciarse -desde la política- de un pasado del que ellos también formaron parte:

No podemos votar por los responsables de este golpe de mano contra el futuro de la democracia y de las opciones cívicas en nuestro país. No podemos votar, ni por Enrique Bolaños, que como vicepresidente ha sido co-responsable de todos los abusos cometidos por el gobierno actual, ni por Daniel Ortega quien, en su ambición de recuperar el poder, ha irrespetado los principios democráticos. Ambos representan el pasado. (Cardenal et al, 2001)22.

La decisión de los autores de usar el concepto de memoria, y no el de autobiografía y/o testimonio en el título de sus libros responde a los cambios en las perspectivas literarias-culturales e incluso políticas de los autores. En general, la autobiografía es vista como una expresión de liberalismo en el que un sujeto narra su propia vida y hace un recuento de ella y de su obra. Aquí, el hombre protagonista es percibido como un sujeto político capaz de hacer historia, por lo tanto, tiene su anclaje en el sujeto de expresión liberal, con el que no se sentiría cómodo ninguno de estos participantes de la revolución sandinista. ${ }^{23}$ Los autores referidos tienen un acercamiento teórico, profesional, militante y personal con la producción y desarrollo de las obras testimoniales, por lo que se distanciaron del término, el cual está estrechamente relacionado con los movimientos de izquierda de los años sesenta, setenta y ochenta, un periodo "superado" por ellos.

Hay una dicotomía que se desprende del título de sus obras, pues buscan romper con un capital literario, que seguramente ven como estrecho pues han evolucionado en su proceso cultural y creativo desde las artes ${ }^{24}$. No obstante, el espectro político sigue vigente y ellos como agentes involucrados en él, no se escinden completamente de los significados del testimonio, y sigue operando en sus textos, políticamente se sitúan fuera de las concepciones percibidas como obsoletas y fracasadas de un pasado reciente que se atribuye como continuidades del proyecto partidista del FSLN, lo que los lleva a ubicarse

\footnotetext{
${ }^{21}$ Una de las características más significativas de la posguerra fue el deseo del gobierno de Managua con Arnoldo Alemán a la cabeza de erradicar el memorial sandinista de la nomenclatura de la ciudad, al mismo tiempo que se llamó al periodo "la noche oscura de Nicaragua”. Sobre el tema puede verse Rueda, 2006.

$\underline{22}$ En el desplegado conjunto citado en el texto, no se asume que la democracia actual también fue obra de quienes lo suscriben -principalmente de Ramírez, que además de ex vice-presidente fue diputado de oposición-, que ellos, aunque alejados del poder político, son miembros del poder intelectual, y que también representan el pasado, pues fueron ministros, políticos, dirigentes y embajadores propagandísticos de la revolución.

${ }^{23}$ En Nicaragua el liberalismo es un concepto-idea estrechamente relacionado con la dinastía de los Somoza.

${ }^{24}$ Adiós muchachos de Sergio Ramírez tiene como subtítulo Una memoria de la revolución sandinista, intentando con ello tres tareas simultáneas: hacer hablar a la revolución a través de él, escribir desde su memoria, e inscribirse a sí mismo en la historia de la revolución. Sobre el tema véase Rueda, 2005.
} 
e identificarse con el paradigma del verdadero sandinismo; conocedores del lenguaje y el análisis del testimonio, distinguen a la autobiografía como un expresión literaria que contiene los cánones occidentales de construcción del sujeto individual contrario a la construcción colectiva del yo, para asegurar con ello, su integración a la cultura hegemónica, contraria a los ideales del proyecto revolucionario sandinista, lo que significaría la apostasía de la ideología que continúan pretendiendo exaltar. En tal sentido, el concepto de memoria e incluso el de confesión es visto desde una perspectiva que incluye la tradición, pero al mismo tiempo abre nuevos horizontes de creación y libertad artística.

En los tres casos mencionados se trata de un tipo de narrador que ha podido penetrar en sus recuerdos y los organiza en el relato de los acontecimientos, los mismos que se imponen a través de la memoria y que autorizan a creerlos por estar en las zonas de confesión afectiva de la experiencia y por su cercanía con los hechos históricos, y por lo tanto, con la disciplina histórica, así como, apelan a la autoridad moral y política que erigieron durante el ejercicio de sus funciones en la revolución y el gobierno emanado de esta. Como testimonio, pretende tener un valor de verdad (Prada, 2001: 11). Efectivamente, la intención de Ramírez -de Cardenal y de Belli- es que la revolución sea recordada y él la recuerda a través de un documento de vida real como una práctica ideológica específica (Beverley, 1988: 7). Por consiguiente, existen dos niveles de lectura superpuestos: por un lado, el de la experiencia individual y, por otro, la lectura dentro de lo social, pues las ricas experiencias pasadas seguirán siendo significativas y recurrentes, pero los protagonistas se vieron obligados a cambiar sus paradigmas narrativos.

Podemos decir que el desarrollo de la producción testimonial sandinista flanqueó también los momentos del proceso revolucionario, puso énfasis en legitimar la lucha antisomocista y el proyecto del FSLN en la construcción de una nueva Nicaragua; participó en el proceso cultural latinoamericano de los distintos movimientos de Liberación Nacional; exploró, exaltando su propia identidad, los recursos del arquetipo testimonial que configuró la intelectualidad de izquierda y que legitimó su existencia desde la academia y el campo cultural. El proceso de democratización en la región -posterior a los Acuerdos de Paz y la derrota del FSLN en las urnas-, como fin de las luchas antidictatoriales, y los nuevos comicios electorales, obligaron a interrumpir la creación de obras con los mismos recursos, puesto que era necesario una reformulación de su naturaleza, por lo que la autocrítica fue obligada, así como el replantearse sus razones de lucha; así el testimonio como arma de guerra, perdió la fuerza que tuvo en las décadas de los años setenta y ochenta. No obstante, su uso político continúa estando vigente, en tanto que los silencios, las exclusiones, omisiones y exageraciones son conscientes. El tema contrarrevolucionario y la llamada Contra, como antagonistas del proyecto sandinista, así como sus ideas, sus protagonistas, sus dirigentes y sus historias quedaron ausentes, y se configura como representación de la otredad que debe ser exterminada, para asegurar la propia sobrevivencia. 


\section{Testimonios contrarrevolucionarios}

Si bien la hegemonía del testimonio sandinista es innegable, durante la década revolucionaria se escribieron algunos textos que contrastaban con la versión de ésta, asimismo la posguerra permitió que fuera posible la edición y distribución de textos con algunas de las características de los de la izquierda, pero elaborados con elementos de un discurso contrarrevolucionario. En ese sentido, el concepto de testimonio como literatura de resistencia sigue siendo válido, pues se trató de textos que se oponían a la hegemonía sandinista, que pretendió dar voz al otro, al sujeto subalterno o marginal ausente de la historia y de los discursos oficiales del FSLN, ubicando a esta identidad como la cultura dominante. Al incluir estas voces se pretendió construir una historia en la que el "pueblo" contrarrevolucionario estuviera presente como sujeto histórico y como protagonista de los procesos de liberación nacional ${ }^{25}$.

Estos textos son numéricamente reducidos pero es preciso resaltar su importancia puesto que fueron elaborados por ex combatientes, líderes y simpatizantes de La Contra en un contexto de contraposición al sandinismo dominante, lo que significó una limitada distribución tanto en Nicaragua como en los Estados Unidos, y por supuesto, en Latinoamérica lo que puntualiza la poca importancia que se les ha dado, aún después de la derrota electoral. Es necesario mencionar que La Contra utilizó una gran cantidad de recursos para financiar la Revista Resistencia que como contraste tuvo distribución controlada y limitada en ambos países.

Estas versiones contrarrevolucionarias a las que hacemos mención contrastan y se confrontan con la historia romántica del sandinismo, reproducida por sus militantes o sus apologistas, y las buenas nuevas de la revolución pusieron de manifiesto la violencia en el campo como escenario de guerra, así como, lo significativo de los ataques de La Contra mismos que se intensificaron y que obligaron al gobierno nicaragüense a abrir paulatinamente las posibilidades de la negociación. Ello debido también a las presiones internacionales y al recrudecimiento de la crisis económica que se intensificó por los recursos destinados a sostener la lucha contra estos grupos rebeldes unificados en la Resistencia Nicaragüense (RN). Fue entonces que empezaron a escucharse algunas voces disidentes del sandinismo a través de sus testimonios.

La construcción de una narrativa contrarrevolucionaria no es tarea sencilla, existe la imposibilidad de unificar los discursos de los contras, ello por la gran cantidad de grupos que tomaron las armas en contra de la revolución y cuyo único elemento en común era su antisandinismo activo, así surgen

\footnotetext{
${ }^{25}$ Hay que recordar que en el discurso contrarrevolucionario sobresale la idea de que el sandinismo era una forma de pie de playa en Centroamérica para la instauración del comunismo financiado por la URSS y Cuba, por lo tanto la lucha contrarrevolucionaria era una forma de liberación nacional de las garras comunistas.
} 
entonces las Fuerzas Armadas Democráticas (FAD), la Unión Democrática Nacional-Fuerzas Armadas Resistencia Nicaragüense (UDN-FARN), la Legión 15 de Septiembre, la Alianza Democrática Revolucionaria Nicaragüense (ADREN), la Unión Democrática Nicaragüense (UDN), las Fuerzas Armadas Revolucionarias Nicaragüenses (FARN) y en el Caribe, las Fuerzas Armadas Anticomunistas, Yaspi Tarba Masraka Nahin Asalatanka (YATAMA), Miskitos, Sumus y Ramas (MISURA) y Alianza Revolucionaria Democrática (ARDE), entre otros.

Muchas de estas organizaciones se unificarían -no sin pugnas internas- en el Frente Democrático Nicaragüense (FDN). Estos grupos eran diversos, estaban presentes los ex guardias somocistas, los somocistas, los desertores del sandinismo, luego se sumarían contingentes campesinos e indígenas, mujeres y adolescentes con discursos propios que fueron subsumidos en la retórica sandinista oficial que los llamó simplemente contrarrevolucionarios y cuyas organizaciones, intereses y reivindicaciones no fueron diferenciadas. Estos grupos fueron reconocidos internacionalmente bajo el nombre de $L a$ Contra, ello a pesar de que a partir de 1987 se unificarían y se llamarían oficialmente Resistencia Nicaragüense (RN) (Castillo Rivas, 1993: 20).

Sobre los escasos testimonios Contras entre 1979 y 1990 se escribieron los siguientes textos: destacando en primer lugar, la obra de José Antonio Robleto Siles, Yo deserté de la Guardia Nacional (1979), que narra - como el título infiere- la experiencia de un ex guardia que deserta del somocismo ante los excesos de su cuerpo militar y que sirvió, sin lugar a dudas, como propaganda sandinista, está también Memoirs of a conter-revolutionary. Life with de contras, the sandinistas and the CIA (1989) de Arturo Cruz Jr., que relata cómo después de haber sido un simpatizante sandinista rompe con la cúpula del gobierno para irse a combatir con la contrarrevolución.

También deben mencionarse Contra Terror in Nicaragua: Report of a fact-finding misión: september 1984 (1985), es un trabajo elaborado por el internacionalista Brody Reed que, si bien, pone en énfasis las violentas acciones de La Contra, en el brutal impacto entre la población y en el pernicioso efecto del financiamiento norteamericano, también deja ver la presencia de campesinos nicaragüenses en el movimiento, lo que trastoca y cuestiona uno de los mitos más difundidos por el FSLN, que La Contra estaba conformada únicamente por mercenarios y ex guardias somocistas al servicio del imperio norteamericano, por último, el ambivalente texto Agonía en el bunker del Cardenal de Nicaragua Miguel Obando y Bravo (1990) un detractor del FSLN que posteriormente hará alianzas con Daniel Ortega.

Dentro del discurso de apoyo al sandinismo y, por lo tanto, en el paradigma testimonial desde el poder, pero que significativamente buscó los argumentos que explicarán el levantamiento Contra, destacan dos libros. En primer lugar encontramos el texto Confesiones de un contra: historia de "Moises" de la periodista sudamericana Elizabeth Reimann (1986) y Yo fui un contra: historia de un paladín de la 
libertad de la misma autora en colaboración con el dirigente de la Fuerza Democrática Nicaragüense (FDN), José Efrén Martínez Mondragón (1987). Estos libros son importantes pues tal como apunta Leonel Delgado (2014) la memoria del sandinismo es una memoria en cierto sentido institucional o gubernamental con poco o nulo espacio a las voces disidentes o no oficialistas, y estos libros ejemplifican el poco espacio que se dio a los disidentes.

La derrota electoral del sandinismo abrió nuevos espacios de circulación para estos relatos, algunos testimonios contrarrevolucionarios pueden ser encontrados con relativa facilidad en bibliotecas y otros más en librerías de Nicaragua. De los que gozan un poco de difusión destacan los siguientes: En primer lugar, el significativo texto de Alejandro Bendaña Una tragedia campesina: testimonios de la resistencia (1991), se trata del primer libro en el que se escuchan las voces de los campesinos antisandinistas, y no solo de sus líderes desde una perspectiva revolucionaria, y pone el énfasis en la raíz campesina del movimiento y en la problemática de la propiedad de la tierra como factor central del levantamiento.

Otro texto que intenta explicar el origen de La Contra, las razones de su lucha y el impacto del financiamiento norteamericano en el grupo es la obra de Jaime Morales Carazo La contra. Anatomía de una múltiple traición. ¿Bahía de Cochinos de Reagan? (1989), ahí el líder contrarrevolucionario mezcla su testimonio con una serie de datos y cifras sobre la política norteamericana hacia Centroamérica y lo que considera es la traición del gobierno norteamericano al forzar a la Resistencia Nicaragüense (RN) a negociar con los sandinistas cuando la victoria era, según él, posible. Se mezclan acuciosos datos con impresiones y vivencias del que posteriormente será vicepresidente de Nicaragua en el gobierno de Daniel Ortega de 2006, si bien el texto no es propiamente un testimonio, si tiene algunas características de la literatura testimonial, ahí rescata el papel fundamental de los campesinos llamándolos La Contra patriótica, diferenciándola de la Contra del Directorio Político aliada incondicional de los norteamericanos.

Con la línea argumental del campesinado, pero desde un plano más académico, están las ediciones norteamericanas de los dos trabajos del ex-empleado de la CIA y encargado de colaborar con La Contra desde el territorio hondureño, Timothy Brown, en The real Contra war. Higlander peasant resistence in Nicaragua (2001). La obra fue escrita como tesis doctoral en 1999 basada en los testimonios de varios contras que después conformarían la Asociación Cívica Resistencia Nicaragüense (ACRN), incluye, además, su propia experiencia para lograr una historización de las primeras Milicias Populares Anti- 
Sandinistas (MILPAS) y una radiografía de La Contra ${ }^{26}$. También de Timothy C. Brown -traductor y editor- When the AK-47s fall silent. Revolutionaries, guerrillas, and the dangerous of peace (2000) texto que es el resultado de un encuentro entre ex-guerrilleros de distintas facciones de Centroamérica que han retornado a la vida civil. A través de los distintos capítulos que conforman el libro, se narran los peligros actuales de la vida civil como desmovilizados -incluso mayores que en la guerra- y sus ideales reconstruidos en la coyuntura de una paz endeble y peligrosa.

Es importante también el testimonio escrito por el asesor de La Contra en Honduras, Sam Dillon, titulado Comandos (1991) que narra en primera persona la historia de Luis Fley un oficial rural sandinista que después ingresa a La Contra, ahí es nombrado "Contra's top investigator" encargado de documentar algunos de los abusos cometidos por los comandos de la Resistencia Nicaragüense, posteriormente se benefició de la ambigua Ley de Amnistía concedida por el gobierno de la presidenta Violeta Barrios de Chamorro, que indultó los delitos políticos y conexos. El libro también puede ser leído como la historia de un periodo de aproximadamente 10 años de la RN, pues también incluye otros testimonios de comandos decepcionados.

Está también el texto del opositor sandinista Roberto J. Arguello, La vida secreta de los sandinistas (1997) donde narra, desde el punto de vista de un miembro de una de las familias más tradicionales de Nicaragua, los despilfarros económicos y las inconsistencias intelectuales de los sandinistas, su finalidad es desmitificar "la santidad de la revolución" a través de la denuncia los actos cometidos en contra de los principios democráticos y de ética en los que supuestamente estaba basado su programa de gobierno. A través de su relato, acusa al gobierno de Cuba de injerencista; culpa de debilidad a Violeta Barrios de Chamorro y señala a los hermanos Daniel y Humberto Ortega Saavedra como agentes al servicio de la ex URSS y de Cuba. Incluso, menciona que Daniel Ortega, para representar la categoría de combatiente revolucionario y exaltar su grado de comandante guerrillero, utilizó una barba y que aparecía sucio para aparentar que estaba combatiendo contra Somoza en las trincheras cuando en realidad tenía años de no hacerlo pues vivía cómodamente en Costa Rica. Se trata de un libro totalmente visceral y de desprestigio a todas las figuras políticas de Nicaragua, pero que apunta a una temática que será constante entre los antisandinistas: el enriquecimiento de la cúpula del FSLN que utilizó su hegemonía política para lograrlo.

\footnotetext{
${ }^{26}$ La investigación documental es muy robusta ya que al haber trabajado con el Frente Democrático Nicaragüense (FDN) pudo acceder a los archivos de la organización política. En la introducción se lee que el texto tiene la perspectiva de "a career foreign service officer engaged in the decidedly undiplomatic task of overseein in the field, as I best as i could, a large covert project the world knew as Nicaragua's Contra war". (xv) [...] "This, then, is the story of the unknown Contra War, told for the first time from the perspective of the contras themselves" (p. XVII).
} 
En 1993 se publicó el libro de Donald Castillo Rivas Gringos, Contras y Sandinistas. Testimonio de la Guerra Civil en Nicaragua. Se trata de un intento importante de historizar a La Contra tomando algunos testimonios de líderes contrarrevolucionarios incluido el de su autor, un economista graduado en Cuba, que hizo trabajo internacional para el FSLN con quien rompe después de la victoria para irse a La Contra. También está el libro Fui un combatiente contra el comunismo en Nicaragua en los años 80 de Johnny Gadea (2013) que se inscribe paralelamente en dos caracterizaciones del testimonio, por un lado, el marco ideológico del texto se refiere al periodo de lucha anticomunista de los liberales más tradicionales en Nicaragua (la década revolucionaria), dejando de lado las reivindicaciones campesinas e indígenas de los comandos e inscribiéndolo en el discurso más beneficioso para los intereses norteamericanos: el levantamiento Contra como parte de las batallas del liberalismo centroamericano por desaparecer los intereses comunistas en la zona. La otra caracterización del texto es la necesidad de reivindicar las luchas del protagonista y sus motivaciones, alejándose de los intentos de representación del "otro", en este caso Los contras, y destacando el papel fundamental de Gadea en la lucha anticomunista. Aunque los recursos utilizados en su producción pueden contener elementos del paradigma testimonial, también esta obra se inserta en la literatura anticomunista que se utilizó en la región como propaganda política, y que puede percibirse desde la utilización de vocablos que actúan como símbolos en el título, es decir, el comunismo, como causa de su lucha legítima. Así para el autor, el enfrentamiento sandinistas-contras en Nicaragua trasciende la problemática nacional y la ubica en el conflicto comunismo-anticomunismo que se da en el plano internacional. En ese sentido, es evidente que se inscribe en una globalización política pero también en la emergencia de discursos menos globalizantes y más individuales, una corriente que desde el sandinismo desarrolló Sergio Ramírez, Ernesto Cardenal y Gioconda Belli entre otros, aunque con grandes diferencias ideológicas y de capacidad creativa principalmente por los recursos literarios limitados de Gadea ${ }^{27}$.

Existen además tres textos, que si bien no son contrarrevolucionarios si son críticos a la revolución: el del sacerdote, académico y ex rector de la UCA Xabier Gorostiaga, Dando razón de nuestra esperanza (1991) donde diversos simpatizantes y dirigentes medios del FSLN analizan la derrota electoral, lo que han vivido y lo que esperan de un "nuevo sandinismo" y lo que se vislumbra como una crítica a algunas decisiones del FSLN; las memorias del norteamericano solidario John Brentlinger, The

${ }^{27}$ Sobre el tema véase Delgado (2014) y Rueda (2005) 
best of what we are. Reflections on the Nicaraguan Revolution $(1995)^{28}$, donde logra explicar al lector los últimos años en la historia de Nicaragua; así como el texto de Liebel Manfred, Testimonios de niños, niñas y adolescentes trabajadores de Nicaragua $(1996)^{29}$, en el que se da cuenta de la terrible explotación de la que son objeto los menores nicaragüenses bajo el amparo de la democracia electoral.

Los testimonios de este período son los que se siguen escribiendo y publicando actualmente y que conforman un corpus en desarrollo que dará muchos elementos para nuevos análisis de la evolución del género y sus variantes. Los cambios sociales en Nicaragua influyeron para la conformación -también en desarrollo- de nuevas propuestas literarias que retoman la tradición testimonial a través de las llamadas novela-testimoniales, novelas testimonio y en el testimonio con forma de novela (Morales, 2000:27).

\section{Conclusiones}

El testimonio nicaragüense está estrechamente vinculado con el sandinismo, se trata de una forma literaria desarrollada en el marco de una realidad netamente nicaragüense, nacionalista e ideológicamente representativa de los sectores más marginados de la sociedad, de una época de lucha reivindicativa de los sectores populares y de la disidencia política. La tradición política nicaragüense tiene como característica su bipolaridad, primero fue de liberales contra conservadores -en la historiografía se les llama las paralelas históricas-, de nacionalistas (Sandino) contra imperialistas, de sandinistas contra somocistas, y luego de los contras oponiéndose a los sandinistas. Se trata entonces de proyectos políticos que impactan en lo literario, pues el testimonio se convirtió en una forma de lucha ideológica, de abierta resistencia ante las barbaridades de las autoridades y en busca de la solidaridad internacional. Así la revolución sandinista victoriosa fue el marco ideal para una versión reivindicativa de lo popular, los hombres y mujeres comunes como sujetos de la historia, como agentes del cambio y protagonistas de la revolución que dejan huella en el sandinismo porque es su proyecto.

El proyecto enarbolado por sandinismo y su realidad como gobierno revolucionario también tuvieron sus detractores, y al ser estos últimos una minoría -aunque financiada internacionalmente- su discurso y propuestas quedaron subsumidas por la prédica oficial, primero de sus agentes financieros y

\footnotetext{
${ }^{28}$ Profunda y amena reflexión sobre la revolución sandinista y sus múltiples significados para la población nicaragüense e internacional. Es el testimonio y el análisis de un norteamericano solidario que dejó varios años, sus esperanzas y sueños en la revolución. Pero si él se siente defraudado ¿qué siente la gente que perdió algo más que las ilusiones? y dan su testimonio los taxistas, las madres, los que participaron en el Servicio Militar Patriótico (SMP) y en general la gente que vivió y padeció esos años.

${ }^{29}$ La obra ejemplifica desde la perspectiva de los menores la terrible crisis económica nicaragüense en la primera mitad de la década de los noventa y cómo esta situación es más una constante que un hecho aislado para una generación que padeció la guerra y posteriormente las severas políticas de ajuste económico de la democracia a la nicaragüense.
} 
después por el gobierno nicaragüense. Si a ello se suma el poco interés de los mismos contras por hacer oír su voz para separarse de los intereses norteamericanos y de hacer patentes sus reivindicaciones, el resultado es un silencio testimonial profundo, mismo que sin embargo ha sido roto por cierta voces que han intentado dejar textos donde expliquen y se expliquen a sí mismos los avatares de la lucha contrarrevolucionaria, así como las críticas profundas a los sandinistas y hacer patentes los errores del proceso revolucionario y también de la lucha contra.

Al finalizar la lucha armada antiimperialista, las formas literarias desarrolladas durante la revolución sandinista resultaron caducas; no obstante, la innovación no pudo romper por completo con la tradición, así como la reconstrucción del sistema político en el país centroamericano se alejó de la utopía transformadora que había cobijado a buena parte de Latinoamérica, la necesidad de escuchar y hacerse escuchar siguió siendo parte fundamental de los grupos excluidos que a través de escritos narran la violenta realidad de la posguerra.

Con el fin de la guerra tampoco desparecieron las manifestaciones de pobreza, explotación, exclusión, dependencia, autoritarismo, entre otras tantas condiciones difíciles, sin embargo, tal como sucedió en las décadas pasadas, el sistema político -ahora de la posguerra- ha minimizado las expresiones políticas radicales que caracterizaron los años de apogeo y predominancia del testimonio como expresión de los grupos marginales. Sin embargo, el testimonio ha sido y es, una práctica cultural, que si bien en un principio sirvió para exaltar la izquierda revolucionaria, las características específicas de Nicaragua -la única revolución triunfante después de Cuba, el surgimiento de la guerrilla contrainsurgente- se modificó, situando en un primer momento a los sujetos o colectividades involucradas en el relato en el lugar del "otro" (los guerrilleros, las mujeres, los indígenas, los campesinos, etc.) pero desconociendo y apartándose de las causas, ideologías, de un "otro” (los contras) que siguieron siendo marginales.

El testimonio nicaragüense es un corpus en evolución, de voces múltiples y diversas que llegó a ser canónico durante el sandinismo triunfante, sin embargo, aún están las voces contrarrevolucionarias que buscan abrir un espacio que les ha sido negado, pues fueron parte fundamental de la historia de ese país, de los avatares de la década revolucionaria y son protagonistas también de la posguerra, es por ello que varios contras han escrito y difundido sus textos en editoriales pequeñas, en ediciones financiadas y distribuidas por ellos mismos, lo que si bien limita su difusión es una expresión de su intención de ser incluidos en el memorial nicaragüense. En definitiva es necesaria y pertinente la construcción de una memoria contrarrevolucionaria que sin lugar a dudas será polémica. 
Verónica Rueda y Juan Carlos Vázquez. Testimonio nicaragüense...

\section{Bibliografía}

Alexander, Alfonso (1937). Sandino: relato de la revolución en Nicaragua. Santiago de Chile: Ercilla.

Arellano, Jorge Eduardo (1997). Panorama de la literatura nicaragüense. Managua: Ediciones Nacionales, reimpresión de la obra de 1977 corregida y puesta al día.

Arguello, Roberto J. (1997). La vida secreta de los sandinistas. Miami: USA, 2a edición de1997, RJA Editores.

Barnet, Miguel (1968). Biografía de un cimarrón. Barcelona: Editorial Ariel.

Barnet, Miguel (1969). La fuente viva. La Habana, Cuba: Editorial letras cubanas, Colección crítica.

Belausteguigoitia, Ramón (1934). Con Sandino en Nicaragua. Managua: Editorial Nueva Nicaragua, edición de 1985.

Belli, Gioconda (2001). El país bajo mi piel: Memorias de amor y guerra. Barcelona: Plaza y Janés Editores.

Bendaña, Alejandro (1991). Una Tragedia Campesina. Testimonios de la Resistencia. Managua: Editora de Arte (Edit-arte) y Centro de Estudios Internacionales (CEI).

Beverley, John (1999). “Algunos apuntes sobre la relación literatura-revolución en el caso nicaragüense”. (Román-Lagunas, ed.). Visiones y revisiones de la literatura centroamericana. Guatemala: Colección Centro Internacional de Literatura Centroamericana, volumen 3, Editorial Oscar de León Palacios: 13-28.

Beverley, John. “El Testimonio en la Encrucijada”. Revista Iberoamericana164-165 (1998): 485-495.

Beverley, John (1992). “Introducción” Revista de Crítica Literaria Latinoamericana. Número especial. La voz del otro: testimonio, subalternidad y verdad narrativa. (Hugo Achúgar y Jonh Beverley) 36 (1992): 7-18.

Beverley, John, Zimmerman, Marc (1990). Literature and politics in the Central American Revolutions. USA: Austin, Texas, United Press.

Borge, Tomás (1989). La paciente impaciencia, Managua: Editorial Vanguardia.

Burgos, Elizabeth (1983). Me llamo Rigoberta Menchú y así me nació la conciencia. Barcelona: Seix Barral.

Brown, Timothy (2001). The real contra war. Higlander peasant Resistence in Nicaragua. USA: University of Oklahoma.

Brown, Timothy (2000). When the AK-47s Fall Silent. Revolutionaries, Guerrillas, and the Dangerous of 
Verónica Rueda y Juan Carlos Vázquez. Testimonio nicaragüense...

Peace. Hoover Institution Press: Stanford University.

Brentlinger John (1995). The best of what we are. Reflections on the Nicaraguan Revolution. USA: The University of Massachussets Press.

Cabestrero, Teófilo (1985). Nicaragua: Crónica de una sangre inocente. México: Editorial Katún.

Cabestrero, Teófilo (1983a) Revolucionarios por el evangelio, Bilbao, España: Artes Gráficas Grijelmo.

Cabezas, Omar (1982). La montaña es algo más que una inmensa estepa verde. Managua: Editorial Nueva Nicaragua.

Cannabrava Filho, Paulo (1978). Tras los pasos de Sandino. Nicaragua 1978. Madrid: Encuentro ediciones.

Cardenal, Ernesto (2003). La Revolución Pérdida. Madrid: Editorial Trotta.

Cardenal, Ernesto (2001). Las Ínsulas Extrañas. México: Fondo de Cultura Económica.

Cardenal. et al. "No votaremos". La Nación, (14/ 10/2001).

Cardenal, Ernesto (1999). Vida perdida. México: Fondo de Cultura Económica.

Castillo Rivas Donald (1993). Gringos, contras y sandinistas: testimonios de la guerra civil en Nicaragua. Colombia: Tercer Mundo Editores.

Cruz, Arturo Jr. (1989). Memoirs of A Counter-Revolutionary. Life with the Contras, the Sandinistas and the CIA. New York, USA: Doubleday.

Chamorro Cuadra, Pedro Joaquín (1963). Diario de un preso. Managua: Editorial Nuevos Horizontes.

Chamorro Cuadra, Pedro Joaquín (1957). Estirpe Sangrienta. Los Somoza. México: Ediciones Patria y Libertad.

Cuadra, Manolo (1942) Contra Sandino en las montañas. Managua: Nuevos horizontes.

Dillon, Sam (1991). Comandos. New York, USA: Published by Henry Holt and Company.

Dalton, Roque (1972). Miguel Mármol. Los sucesos de 1932 en El Salvador. México: ediciones Cuicuilco, serie testimonios, ENAH-INAH, edición de 1982.

De Certeau, Michael (1994). "La operación histórica". (Perus, Francoise, eda.). Historia y literatura. México: Instituto Mora, Antologías Universitarias: 31-69

Delgado Aburto, Leonel. "Memorias apocalípticas, administrativas y campesinas: por una crítica de la memoria del sandinismo". Meridional. Revista chilena de Estudios Latinoamericanos 2 (2014): $107-131$. 
Delgado Aburto, Leonel (2002). “Apuntes sobre procesos culturales y literatura Nicaragüense del S.XX”. Istmo. Revista virtual de estudios literarios y culturales centroamericanos 2 (2012).

Delgado Aburto, Leonel (2002a). Márgenes recorridos: Apuntes sobre procesos culturales y literatura Nicaragüense del S.XX. Managua: primera edición, IHNCA-UCA.

Ferro, Roberto (1998). La ficción. Un caso de sonambulismo teórico. Buenos Aires: Editorial Biblos.

Fonseca Amador, Carlos (entre 1958 y 1961). Un Nicaragüense en Moscú. Managua: Centro de Publicaciones de la Secretaria Nacional de Propaganda y Educación Política, edición de 1980.

Franco, Marina (2014). "La “teoría de los dos demonios”: un símbolo de la posdictadura Argentina”. A contra corriente. Revista de historia social y literatura en América Latina 11/ 2 (2014): 22-52.

Gadea, Johny (2013). Fui un combatiente contra el comunismo en Nicaragua en los años 80. Indiana: Editorial Palibro, Distribución del autor.

Gliemmo, Graciela (1996). "Hacer la Historia: particularidades de los testimonios escritos por sus protagonistas”. Frontera Literarias en América Latina, Instituto de Literatura Hispanoamericana. Universidad de Buenos Aires.

Gonzaga Cardenal, Luis (1961). Mi rebelión. La dictadura de los Somoza. México: Ediciones Patria y Libertad.

Gorostiaga, Xabier et.al (1991). Dando razón de nuestra esperanza. Managua: Ediciones Nicarao.

Harlow, Barbara, (1999). "Cárceles clandestinas: interrogación, debate y diálogo en El Salvador". (Román-Lagunas, Jorge y Mc Callister, Rick, comp.). La literatura centroamericana como arma cultural. Guatemala: Colección Centro Internacional de Literatura Centroamericana, volumen 1, Editorial Oscar de León Palacios.

Legrás, Horacio (2000). "Criollismo e Indigenismo literarios: Representación sin resto y resto sin representación”. Latin American Literatures: A Comparative History of Cultural Formations. Volume 3, Mario Valdés and Linda Hutcheon, eds. Oxford University Press.

Liebel, Manfred (1996). Testimonios de niños, niñas y adolescentes trabajadores de Nicaragua. Managua: Editorial Nueva Nicaragua.

Maier, Elizabeth (1980). Las sandinistas. México: Ediciones de Cultura Popular.

Maier, Elizabeth(1985). Nicaragua, la mujer en la revolución. México: Ediciones de Cultura Popular. 
Verónica Rueda y Juan Carlos Vázquez. Testimonio nicaragüense...

Mackenbach, Werner (2001). “Historia y ficción en la obra novelística de Sergio Ramírez”. VI Congreso Centroamericano de Historia, Ciudad de Panamá, 22 - 26 de julio de 2002 en Istmo. Revista virtual de estudios culturales.

Mackenbach, Werner (2001a). "La nueva novela histórica en Nicaragua y Centroamérica". Istmo. Revista virtual de estudios culturales 1 (2001).

Mackenbach, Werner (2000). "Historia, nación / pueblo e individuo en el testimonio nicaragüense y centroamericano" ponencia del V Congreso Centroamericano de Historia, San Salvador, 18, 19, 20 y 21 de julio en Istmo. Revista virtual de estudios culturales.

Molloy, Silvia (2001). Acto de presencia. La escritura autobiográfica en Hispanoamérica. México: Fondo de Cultura Económica-COLMEX.

Monsiváis, Carlos. "La Revolución Cubana: los años del consenso". Revista Encuentro 16/17 (2000).

Morales Carazo, Jaime (1989). La contra. Anatomía de una múltiple traición. ¿Bahía de Cochinos de Reagan?México: Editorial Planeta, colección documento.

Morales, Mario Roberto (2001). Introducción al libro Stoll-Menchu: la invención de la memoria. Guatemala: Editorial Consucultura.

Morales, Mario Roberto (2000). "Entre la verdad y la alucinación: novela y testimonio en Centroamérica”. (Román-Lagunas, Jorge y Mc Callister, Rick, comp.)La literatura centroamericana como arma cultural, Guatemala, Colección Centro Internacional de Literatura Centroamericana, volumen 1, Editorial Oscar de León Palacios.

Nagy-Zekmi, Silvia. “¿Testimonio o Ficción? Actitudes Académicas”. Ciberletras. Revista literaria virtual 5 (2001).

Obando y Bravo, Miguel (1990). Agonía en el Bunker. Managua: Comisión de Promoción Social Arquidiocesana (COPROSA).

Ochando Aymerich, Carmen (1995). "Hacia la Institucionalización del Testimonio". (Christian Paepe, ed.). Literatura y Poder. Bélgica: Leuven University Press.

Prada Oropeza, Renato (2001). El discurso-testimonio y otros ensayos. México: UNAM, Coordinación de Difusión Cultural/Dirección de Literatura, Serie El Estudio.

Randall, Margaret (1999). Las hïas de Sandino. Una historia abierta. Nicaragua: Anamá ediciones centroamericanas. 
Randall, Margaret (1992). “¿ Qué es, y como se hace un Testimonio”. Revista de Crítica Literaria Latinoamericana, Número especial La voz del otro: testimonio, subalternidad y verdad narrativa. (Hugo Achugar y Jonh Beverley, eds.): 21-45.

Randall, Margaret (1989). Las mujeres. México: Siglo XXI.

Randall, Margaret (1984). Risking a Somersault in the air. Estados Unidos: Rutgers Univerity Press.

Randall, Margaret (1983). Testimonios una co-edición de San José: Centro de Estudios y Publicaciones Alforja y Managua: Editorial Nueva Nicaragua. Manual preparado para el Taller sobre Historia oral del Ministerio de Cultura Sandinista en 1979.

Randall, Margaret (1983a). Cristianos en la revolución. Managua: Editorial Nueva Nicaragua.

Randall, Margaret (1980). Todas estamos despiertas. Testimonios de la mujer nicaragüense hoy. México: Siglo XXI Editores.

Randall, Margaret (1977). Somos millones. La vida de Doris María, combatiente nicaragüense. México: Editorial Extemporáneos, Colección Latinoamérica, Serie testimonio \# 2.

Ramírez, Sergio (1990). “Nicaragua: confesión de amor”. Revista Nexos, México, Agosto.

Ramírez, Sergio (1990). La marca del Zorro: Vida y hazañas del Comandante Francisco Rivera. España: Mondadori, edición original de 1989.

Reed, Brody (1985). Contra Terror in Nicaragua: Report of a fact-finding misión: september 1984. Boston, Masachusets: South End Press.

Reimann, Elizabeth, Martínez Mondragón José Efrel (1986). La: historia de "Moises": yo fui un paladín de la libertad. México: Ediciones El Caballito.

Reimann, Elizabeth, Martínez Mondragón José Efrel (1987). Yo fui un contra: historia de un paladín de la libertad. Nicaragua: Editorial Vanguardia.

Robleto, Hernán (1930). Sangre en el trópico: Novela de la intervención yanqui. Madrid: Editorial Cenit.

Robleto Siles, José Antonio (1979). Yo deserté de la Guardia Nacional. Costa Rica: Ciudad Universitaria Rodrigo Facio y Editorial Universitaria Centroamericana.

Román, José (1930). Maldito país. Managua: Ediciones el Pez y la Serpiente, edición de 1983.

Rueda Estrada, Verónica. "Testimonios, confesiones y memorias del sandinismo". Cuadernos Americanos 127 (2009):145-162. 
Rueda Estrada, Verónica (2006) "El rebelde nicaragüense, la santidad del sandinismo". (Camacho Navarro, Enrique, coord.) El rebelde contemporáneo en el circuncaribe. Imágenes y Representaciones. México: CECYDEL-UNAM, Editorial Edére.

Rueda Estrada, Verónica (2005). Testimonio y confesión. Épica y memoria de la revolución sandinista en La marca del Zorro, Confesión de amor y Adiós muchachos de Sergio Ramírez Mercado. Tesis de maestría en Estudios Latinoamericanos, UNAM, inédita.

Somoza Debayle, Anastasio y Cox, Jack (1980). Nicaragua Traicionada. Boston-Los Angeles: Editorial Western Islands.

Somoza García, Anastasio (1936). El Verdadero Sandino o el calvario de Las Segovias. Managua: Editor Robelo.

Torres Lazo, Agustín (2002). La saga de los Somoza. Historia de un magnicidio. Nicaragua: Hispamer.

Urbina, Nicasio (2001). “La semiótica del testimonio: Signos textuales y extra-textuales”. Istmo. Revista virtual de estudios literarios y culturales centroamericanos 2 (2001).

Yúdice, George (1992). “Testimonio y Concientización”. Revista de Critica Literaria Latinoamericana, Número especial La voz del otro: testimonio, subalternidad y verdad narrativa. (Hugo Achugar y Jonh Beverley, eds.) 36: 207-227. 